EGU21-7849, updated on 26 Apr 2021

https://doi.org/10.5194/egusphere-egu21-7849

EGU General Assembly 2021

(c) Author(s) 2021. This work is distributed under

the Creative Commons Attribution 4.0 License.

\title{
A Hybrid Breaching-Filling method for sink removal adapted to parallel hydrological simulations
}

\author{
sleimane hariri ${ }^{1}$, Jens Gustedt ${ }^{1,2}$, Sylvain Weill ${ }^{3}$, and Isabelle Charpentier ${ }^{1}$ \\ ${ }^{1}$ ICube UMR 7357, Université de Strasbourg \& CNRS, 67412 Illkirch, France \\ ${ }^{2}$ INRIA, France \\ ${ }^{3}$ Institut Terre et Environnement de Strasbourg (ITES)/Earth Environment Strasbourg, UMR 7063, Université de \\ Strasbourg/EOST/ENGEES, CNRS, France
}

Digital Elevation Models (DEMs) are approximations used for hydrological simulations and flood mapping. Usually, DEMs have sinks corresponding to actual landscape depressions and/or engineered structures such as bridges, road embankments, overhangs, dams... over or near to water bodies. These sinks often result from interpolation errors or measurement inaccuracies. Regardless of the source, sinks usually cause issues in hydrological simulations.

Classical filling and breaching methods have shown performance limitations. On one hand, a breaching method cannot deal with big sinks such as sinkholes and lakes in a fair manner as it may yield a long and deeply incised breach channel (lindsay 2016). On the other hand, even though favored among practitioners, filling a sink may yield a flat area whose altitude is the same as its outlet. Therefore, hybrid methods combining breaching and filling were introduced. Lindsay (2016) presented a hybrid method called "Selective breaching" where a threshold sink depth is defined. As noted in Martz and Garbrecht (1999), a flat area near to the drainage basin outlet impacts the computation of flow direction and the subsequent hydrological simulation.

A watershed partition into hydrological sub-units, e.g. (Hariri 2019) allows for the parallelization of hydrological simulations. However, the larger the number of drainage basins and outlets, the more opportunities of having flat areas near outlets are met.

As an automatic mitigation, we propose a hybrid method blending a carved DEM and a filled DEM based on the distance to the outlet to take advantage of both methods.

The impact of the different methods to deal with sinks are evaluated for the Moderbach watershed ( $89 \mathrm{~km}^{2}$, Région Grand-Est, France) chosen for its numerous engineering structures (5 big reservoirs, 6 large dams, 3 flood detention areas, roads and highway) comparing the results produced by a mixed-hybrid finite element code for surface flow simulation (Younes 1999) and HEC-RAS (Brunner 1994). The results show that the hybrid method we proposed overcomes the limitations of the classic filling and breaching and it is well adapted for parallel computing. 
Bibliography

Brunner GW. HEC river analysis system (HEC-RAS). US Army Corps of Engineers, Hydrologic Engineering Center. 1994.

Hariri S, Weill S, Gustedt J, Charpentier I. Pairing GIS and distributed hydrological models using Matlab 2. CAJG - 2nd Conference of the Arabian Journal of Geosiences. 2019 Nov.

Lindsay JB. Efficient hybrid breaching $\square$ filling sink removal methods for flow path enforcement in digital elevation models. Hydrological Processes. 2016 Mar 15;30(6):846-57.

Martz LW, Garbrecht J. An outlet breaching algorithm for the treatment of closed depressions in a raster DEM. Computers \& Geosciences. 1999 Aug 1;25(7):835-44.

Younes A, Mose R, Ackerer P, Chavent G. A new formulation of the mixed finite element method for solving elliptic and parabolic PDE with triangular elements. Journal of Computational Physics. 1999 Feb 10;149(1):148-67. 